\section{Self-punitive behavior with a distinctively marked punishment zone}

\author{
JUDSON S. BROWN \\ University of lowa, Iowa City, Iowa 52240
}

\begin{abstract}
Self-punitive locomotor behavior in rats was investigated in two studies in which the distinctiveness of the punishment zone was manipulated. Contrary to a discrimination hypothesis, conditions designed to enhance the discriminability of the punishment region failed to produce a decrement in vicious-circle behavior. An alternative hypothesis, capable of encompassing both decremental and incremental effects of increased distinctiveness, is proposed.
\end{abstract}

Perseverating self-punitive behavior in a runway has sometimes been attributed to the rat's "failure to discriminate" between the nonelectrified starting area and the shock area. For example, Mowrer (1960), in his analysis of Whiteis's (1956) experiment, concluded: "It is only when they cannot distinguish between the starting and the shock areas of the runway that they get into and persist in the "vicious circle' [p. 487]." Although Whiteis's results supported this conclusion, Gwinn's (1949) did not, and more recent findings have also been contradictory (e.g., Melvin \& Martin, 1966; Smith, Misanin, \& Campbell, 1966). More information is needed, therefore, to evaluate this interpretation. In the experiments reported here, self-punitive running was studied under conditions in which the similarity of the shock segment to adjacent segments was decreased either by adding distinctive stimuli to the alley walls beside the shock zone or by changing the color and texture of the floor of the safe sections.

\section{EXPERIMENT 1}

Shock-escape training in an all gray, 6- $\mathrm{ft}$ runway was followed by extinction trials on which half of the Ss encountered shock in the middle $2-\mathrm{ft}$ segment and half did not. For half of each of these groups, the walls of the shock zone were made distinctive during extinction by the application of black-and-white-striped overlays. For the other half, the walls remained uncovered during extinction.

$$
\text { Subjects }
$$

The Ss were 16 77-day-old male hooded rats of uncertain Long-Evans lineage from the departmental colony at the University of Iowa. Of an original of 20 , one died and three were discarded because of extreme wildness.

\section{Apparatus}

The basic apparatus, described in detail

* Supported in part by NIMH Grant MH-11734-04. The author is indebted to Dr. Eileen M. Beier for a critical reading of the manuscript and to Michael Hacker for statistical assistance. elsewhere (Brown, Martin, \& Morrow, $1964)$, consisted of a grid-floored runway ( $6 \mathrm{ft}$ long, $4.5 \mathrm{in}$. wide, $8 \mathrm{in}$. deep), a two-compartment trap-door-floored starting box, and a large goalbox (18 in. long, 12 in. wide, 8 in. deep). The walls and floor of the goalbox were painted black. All other surfaces, including a subflooring under the grid, were light gray. Photocells and infrared light sources, located at the beginning of the runway and at $2-\mathrm{ft}$ intervals thereafter, operating in conjunction with ancillary equipment, made it possible to obtain precise measurements of starting speed and of locomotor speeds over each of the $2-\mathrm{ft}$ segments. The $60-\mathrm{Hz}$ shock was derived from a variable-voltage autotransformer and applied to the grid through a series resistance of $10,000 \mathrm{ohms}$. The shock intensities specified below represent voltages read with a $2,000-\mathrm{ohm} /$ voltmeter at the grid, with the rat replaced by a dummy load of 100,000 ohms.

\section{Procedure}

All Ss were handled twice a day, for about 2 min each time, for the first 5 days following their arrival in the laboratory area. On the morning of Day 6, they were transported in carrying cages to the experimental room where they were permitted individually to explore the goalbox for about $2 \mathrm{~min}$. During this period they were placed into and picked up from the goalbox about four times. This procedure was duplicated on the afternoon of the same day. The Day 6 procedure was repeated on Day 7 , except that the Ss were permitted to explore the last $2 \mathrm{ft}$ of the runway rather than the goalbox. During the afternoon exploratory period, all recording devices were turned on to accustom the $\mathrm{Ss}$ to the noises produced by those devices.

Escape-training trials were initiated on Day 8. These consisted of 10 shock-escape trials involving progressively longer and longer segments of the runway. On the first two trials the startbox was placed next to the goalbox so that $S$ was required to traverse only a few inches of electrified grid on the floor of the startbox to reach safety in the smooth-floored goalbox. The length of the electrified segment was increased to $2 \mathrm{ft}$ for Trials 3 and 4 , to $4 \mathrm{ft}$ for Trials 5 and 6 , and to $6 \mathrm{ft}$ for the last four trials of the day. The printer mechanism used to provide records of running times was turned on for Trials 9 and 10 to accustom the rats to the clicks produced by that device. The $60-\mathrm{Hz}$ shock voltages were set at 40,50 , and $55 \mathrm{~V}$ for Trials 1-2, 3-6, and 7-10, respectively.

Ten full-length escape-training trials were administered on Day 9. The shock was set at $50 \mathrm{~V}$ for the first five of these and at $55 \mathrm{~V}$ for the last five. The Ss were run in squads of eight with an intertrial interval of about $8 \mathrm{~min}$. One squad was run in the morning and the other in the afternoon. All treatment conditions were represented equally often in each squad.

On the 10th day a single warm-up escape trial $(55 \mathrm{~V})$ was followed immediately by 10 extinction trials. Ten additional extinction trials were administered each day for 5 days thereafter. The extinction criterion was one failure to enter the goalbox within $60 \mathrm{sec}$. For all subsequent trials an extinguished $\mathrm{S}$ was assigned an arbitrary total time of $60 \mathrm{sec}$. This was divided into equal 15 -sec scores for start time and each of the three 2 -ft segment times. Half of the Ss encountered a $55-\mathrm{V}$ shock in the middle 2-ft segment of the runway on these trials and half did not. These punished groups were further divided into subgroups of equal size, which encountered black and white stripes on the walls of the middle 2 -ft segment or simply the usual light-gray walls with which they had been trained up to that point. The black and white stripes were $3 / 4$ in. wide and were vertically oriented on the side walls. For purposes of future reference, the presence of the distinctive cues during extinction is indicated by the letter $\mathrm{C}$, their absence by $\mathrm{NC}$, and the presence and absence of punishing shock by $P$ and NP, respectively. Thus, the four groups are designated P-C, NP-C, P-NC, and NP-NC.

\section{Results}

All segment times were first transformed into speeds in feet/second and a median of each day's speeds was determined for each $S$ for each segment. These individual medians comprised the basic scores from which group medians and means were computed.

The Ss' performances in the middle $2-\mathrm{ft}$ segment where the shock and the distinctive cues were located serve to summarize the results. These data are presented graphically in Fig. 1. Each plotted point is a median of four individual daily medians. Visual inspection indicates 


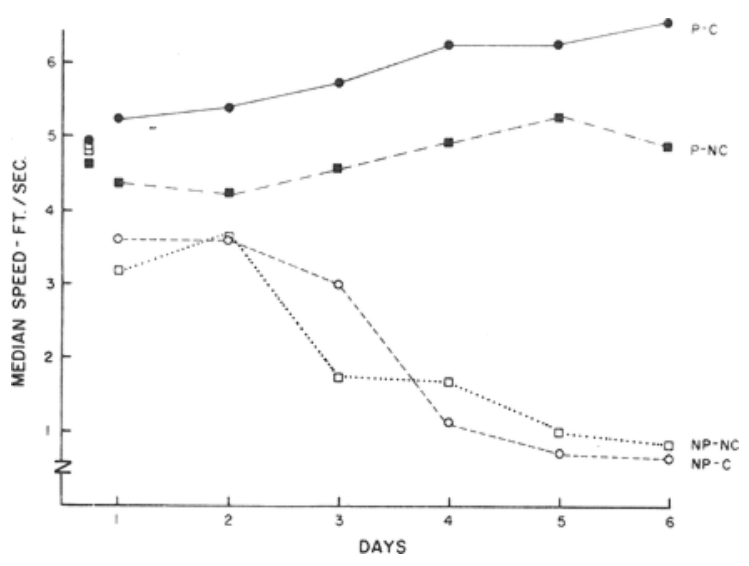

Fig. 1.

that the Ss of the two shocked groups perseverated in running at rather high and nearly constant average speeds throughout the 60 trials of extinction, whereas the nonshocked Ss slowed down progressively and substantially. This is the usual self-punitive effect that has been repeatedly observed under similar conditions. However, contrary to the discrimination hypothesis, the punished group (P-C) that was provided with distinctive cues on the walls of the punishment zone not only continued to run in spite of this aid to discrimination but, in fact, ran somewhat more swiftly than the punished group (P-NC) that had no discriminative stimuli present. The means corresponding to the medians of Fig. 1 were analyzed as a mixed 2 by 2 by 6 factorial with punishment-nonpunishment and cues-noncues as between factors and days as a within factor. Of the between effects, only punishment proved to be significant ( $F=40.38$, df $=1 / 12, p<.001)$, but the within effects of days $(F=6.65$, df $=5 / 60$, $p<.001)$ and the interaction of Days by Punishment $(F=14.02, \quad \mathrm{df}=5 / 60$, $\mathrm{p}<.001)$ were significant. The differences among the groups cannot reasonably be attributed to pretreatment sampling differences, since the groups' mean running speeds over the last three shock-escape trials preceding extinction were essentially identical (see unconnected points at extreme left of Fig. 1).

Parallel analyses of the speed scores in the first and third segments of the runway yielded results comparable to those reported above. The days and the punishment by days effects were significant in both sections, and the punishment effect was significant in the third segment, though not in the first. The main effect of cues was significant at almost the .05 level in the third segment $(F=4.70, \mathrm{df}=1 / 12, \mathrm{p}>.05, \mathrm{~F}$ of 4.75

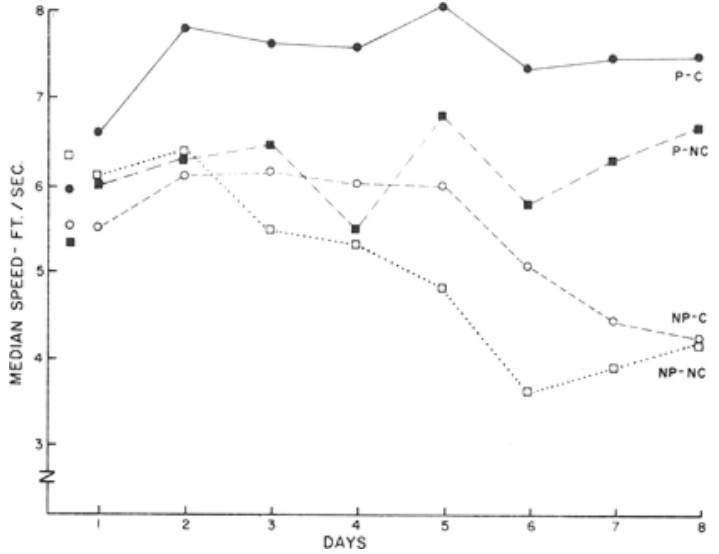

Fig. 2.

needed for $p=.05$ ), with the cue groups running faster than the noncue $S$ s.

The startbox speeds were generally more variable than the running speeds, but they mirrored the latter in that the punished Ss started faster than the nonpunished $\mathrm{Ss}$, especially on the last 2 or 3 days of extinction

The tendency for shock in the middle segment to facilitate rather than interfere with locomotion is indicated by the fact that on the last day of punished extinction all eight of the punished Ss ran faster in the second section than in either the first or third. On the same day the speeds of the nonpunished groups showed almost no appreciable fluctuation attributable to alley segment.

Only three of the $16 \mathrm{Ss}$ met the extinction criterion within the 60 trials. Two of these were in the NP-C group and one was in the NP-NC group. None of the punished Ss extinguished.

\section{Discussion}

The results of this study are consistent with those of previous experiments on self-punitive behavior, since Ss that were shocked during extinction perseverated more in high-speed locomotion than did nonshocked controls. However, contrary to the discrimination hypothesis, Ss continued to approach and cross an electrically energized segment of the runway even when it was marked off from adjacent safe regions by highly distinctive stimuli. Moreover, these Ss actually ran faster (though not significantly) than those of every other group, the margin of superiority being greatest in the distinctive shock region.

Whether an advocate of the discrimination hypothesis could argue that the rats "failed to discriminate" between the black-and-white-striped shock zone and the adjacent gray-walled safe areas is uncertain since there are no generally accepted criteria for asserting that rats have indeed discriminated. However, the stimulus characteristics of the startbox area were quite different from those of the rest of the apparatus, and it is difficult to believe that even without the added cues rats could undergo 60 punished trials without learning that the startbox area was safe relative to the middle section of the runway. The addition of the striped overlays to the walls of the shock region makes this even more improbable. Nevertheless, visual stimuli are apparently not highly salient for the rat, and hence its ability to "discern the difference" between safe and aversive regions should presumably be improved if both the color and the tactual properties of the runway floor were changed. This possibility was explored in the next experiment. EXPERIMENT 2

For half the rats in this study all of the grid floors of the startbox and runway save for the middle 2 -ft section were covered with solid black overlays during extinction. On these trials shock was present in the uncovered section for half the Ss but not for the others.

\section{Subjects}

The Ss were 20 80-day-old female albino rats, Sprague-Dawley derivatives from Carworth Farms.

\section{Procedure}

The first 2 days were devoted to gentling, which consisted of a 1 - to 2 -min handling of each S. On the 3 rd day each $S$ was allowed to explore the goalbox for 1 to 2 min. During this period each $S$ was placed into and removed from the goalbox about four times. None of the recording equipment was turned on. The 4th day's procedures duplicated those of the 3rd save that all recording devices were on and the Plexiglas lid of the goalbox was opened and closed each time $S$ was placed therein. On the 5th day the Ss were given 10 shock-escape training trials in the runway following the procedure used in 
Experiment 1. The $60-\mathrm{Hz}$ shock voltage across the rat was approximately $40 \mathrm{~V}$ for Trials $1-2,45 \mathrm{~V}$ for Trials $3-8$, and $50 \mathrm{~V}$ for Trials 9-10. On the 5 th day every rat was given 10 full-length escape trials with the shock voltage held at 50 .

The first trial of the 6th day, a full-length shock-escape trial, was followed by 10 extinction trials at an intertrial interval of about $7-10 \mathrm{~min}$. For half the $S \mathrm{~s}$ all portions of the alley and startbox grid floors, save for the middle $2-\mathrm{ft}$ alley segment, were overlaid with 1/8-in.-thick Masonite panels. The exposed surfaces of these panels were covered with self-adhering thin sheets of black vinyl (Contact). Thus, for these Ss the stainless-steel grid-bar floor with its light-gray subflooring was transformed on extinction trials to a smooth black floor. The central 2-ft section, of course, remained unchanged. Of the Ss for which the floor cues were changed to black, half were punished with shock in the middle section (Group P.C) and half were not (Group NP-C). Similarly, half the Ss extinguished with no new cues added were shocked (Group P-NC) and the rest were not (Group NP-NC). Due to E error, the last few inches of the 2-ft-long punishment zone were not electrified on shock trials. Results

Segment times were transformed to speeds, and daily medians were determined for each $S$ as in the first experiment. Running speeds from the middle $2 \cdot \mathrm{ft}$ section, which are plotted in Fig. 2, were deemed most appropriate for presentation, inasmuch as shock was located there and especially since the running surface in that segment was the same for all groups. A visual inspection of the curves of Fig. 2 suggests that the findings of the first experiment were essentially confirmed. Once again, Group P-C, for which the punishment zone was distinctive, failed to exhibit the retardation predicted by the discrimination hypothesis and, in fact, ran faster, though not significantly, than the other punished group (P-NC), for which no distinctive cues were present. The superior locomotor speed of the P-C Ss is reflected by the fact that there was no overlap between the distributions of their running speeds and those of the comparable nonpunished group (NP-C) on 6 of the 8 extinction days. The differences among the groups are not attributable, incidentally, to preextinction group differences. The means of the last three escape trials which are plotted as disconnected points at the left of Fig. 2 appear to be unrelated to later performance levels.

An overall analysis of the means corresponding to the medians of Fig. 2 was carried out as a 2 by 2 by 8 factorial with repeated measurements on the last factor. This revealed that shock was a significant source of variance $(F=6.16, d f=1 / 16$, $p=.025)$, as was days $(F=4.88$, $\mathrm{df}=7 / 112, \mathrm{p}=.001$ ), but cues fell short of an acceptable level $(F=3.69$, df $=1 / 16$, $.10>p>.05)$ and no interaction was significant. However, of the 10 shocked Ss in Groups P-C and P-NC, seven ran faster on the eighth day of extinction than on the first; and of the nonshocked Ss (NP-C and NP-NC), eight ran more slowly on the last day than on the first. By Fisher's exact test this interaction was significant $(p=.05$, one-tailed test). Identical tests on the firstand third-segment data were significant at the .025 and .005 levels, respectively.

Measurements of starting speeds and of running speeds in other segments and averages of all segments yielded results that were qualitatively comparable to those shown in Fig. 2. The differences between groups generally were smaller, however, and only the "days" effect was significant in each of the separate analyses.

The discrimination hypothesis leads to the expectation that the P-C Ss would be more likely to extinguish than those of other groups. However, only one S met the extinction criterion of failing to enter the goalbox within $60 \mathrm{sec}$ and that $S$ was a member of the P-NC group.

\section{Discussion}

In this experiment the distinctiveness of the middle segment of the runway was increased by altering both the tactual and visual properties of adjacent regions. Nevertheless, Ss punished in that segment ran as fast-slightly faster, in fact-and as persistently as Ss punished in the same region but without distinctive cues. Neither Experiment 1 nor Experiment 2, therefore, supports the expectation, derived from the discrimination hypothesis, that self-punitive behavior will be attenuated by manipulations that enhance the distinctiveness of the punishment region.

Of some interest is the observation that the members of the P-C group, especially, sometimes hesitated slightly at the leading edge of the shock zone, after which they would leap forward over a portion of the exposed grid floor before continuing on to the goalbox. The high-speed locomotion of the $\mathrm{P}-\mathrm{C}$ rats in the middle section was due in part to these swift forward leaps.

Underlying the discrimination hypothesis is the tacit assumption that an aversive event will necessarily become even more aversive when cues are present to alert the organism to the presence of that event. The findings of the present experiments cast some doubt upon the adequacy of this conception and underscore the need for its revision. As a possible alternative it is suggested that increasing the distinctiveness of a punishment region may either weaken self-punitive behavior, leave it unaltered, or paradoxically, strengthen it. Just which of these results will occur is believed to depend upon the general efficacy of other variables (e.g., shock intensity, shock location, extent and kind of training, etc.) in producing perseverative self-punitive running. When these conditions are unfavorable, as, for example, when punishment is extremely intense, self-punitive behavior should be weakened by augmenting the distinctiveness of the punishment zone. But under highly favorable conditions, the more distinctive the cues denoting the presence or location of punishment, the more pronounced the vicious-circle behavior should be. Increasing the distinctiveness of a bottle of poison by labeling it with a skull and cross-bones may increase its aversiveness for some and may save their lives; but it becomes more attractive to those who, for extraneous reasons, are bent on self-destruction.

\section{REFERENCES}

BROWN, J. S., MARTIN, R. C., \& MORROW, M. W. Self-punitive behavior in the rat: Facilitative effects of punishment on resistance to extinction. Journal of Comparative \& Physiological Psychology, 1964, 57, 127-133. GWINN, G. T. The effects of punishment on acts motivated by fear. Journal of Experimental Psychology, 1949, 39, 260-269.

MELVIN, K. B., \& MARTIN, R. C. Facilitative effect of two modes of punishment on resistance to extinction. Journal of Comparative \& Physiological Psychology, $1966,62,491-494$.

MOWRER, O. H. Learning theory and behavior. New York: Wiley, 1960.

SMITH, N. F., MISANIN, J. R., \& CAMPBELL, B. A. Effect of punishment on extinction of an avoidance response: Facilitation or inhibition? Psychonomic Science, 1966, 4, 271-272.

WHITEIS, U. E. Punishment's influence on fear and avoidance. Harvard Educational Review, $1956,26,360-373$. 